\title{
Impact of COVID-19 Pandemic on Management of Acute Cholecystitis in Singapore
}

\section{Dear Editor,}

The COVID-19 pandemic has brought about profound challenges in Singapore ${ }^{1}$ with surgery drawing scrutiny due to the need to conserve personal protection equipment (PPE), ventilators, intensive care unit (ICU) beds as well as concerns of concurrent COVID-19 infection in surgical patients with reported mortality rate of up to $20 \%$. $^{2}$

Given the scarcity of resources and risks associated with concurrent COVID-19 infection in the surgical patient, international guidelines have recommended medical treatment for acute issues related to cholelithiasis that are normally treated surgically. ${ }^{3}$ This stance has implications on the management of acute cholecystitis (AC) with meta-analyses demonstrating conclusive benefits of index admission early laparoscopic cholecystectomy (ELC) over interval delayed laparoscopic cholecystectomy (DLC) that include decreased total length of stay, decreased readmission for persistent pain and gallstone-related morbidity, earlier return to work, improved quality of life and increased cost-effectiveness., ${ }^{4,5}$ The need to balance the surgical risk and resource considerations of acute cholecystitis with the obligations of delivering optimal outcomes and avoiding morbidity thus poses an ethical dilemma during this pandemic.

With the rapidly evolving pandemic coupled with different subspecialty surgeons managing AC in Singapore, opinions and practices may inevitably vary among institutions and surgeons. Resource and manpower constraints would also translate to changing practices on the ground. Thus, the aim of this study is to evaluate the impact of COVID-19 on the management of AC in Singapore.

An anonymous online survey was developed and disseminated across all seven public restructured hospitals in Singapore in April 2020 via electronic mail. Inclusion criteria was consultant specialist surgeons who perform laparoscopic cholecystectomy in Singapore. The survey was administered through an online platform, Google Forms (Google LLC, Menlo Park, California, USA). The survey includes questions on demographics of survey respondents, impact of the
COVID-19 pandemic on management of AC, screening, use of PPE and questions on resident training.

Acute cholecystitis and the grading of severity were defined in accordance to the Tokyo Guidelines 2018. ${ }^{6}$ Complicated cholecystitis was defined as gangrenous cholecystitis, emphysematous cholecystitis or cholecystitis with presence of abscess. There was a total of 51 respondents out of 73 administered surveys $(69.9 \%)$. The institution, grade and subspecialty of respondents are summarised in Fig. 1. Screening and PPE use is summarised in Table 1. Most respondents perform targeted screening only for patients with respiratory symptoms for COVID-19 (88.2\%) preoperatively. Only $51 \%$ of consultants would use N95 mask and goggles for COVID-19 negative patients. For COVID-19 positive patients, choice of PPE usage differs with 52.9\% using powered air-purifying respirator (PAPR) and 47.1\% using N95 mask with goggles.

Management of uncomplicated and haemodynamically stable complicated AC is summarised in Table 2. Majority of respondents perform ELC for uncomplicated AC $(90.2 \%)$ but this decreased to $58.8 \%$ during the pandemic. Majority $(70.6 \%)$ of respondents felt that testing all patients for COVID-19 will alter their management. Most respondents (92.2\%) would perform ELC for haemodynamically stable complicated AC but this decreased to $66.7 \%$ during the pandemic. For patients requiring $\mathrm{DLC}$ for $\mathrm{AC}$, the duration of interval cholecystectomy varies from less than 6 weeks to more than 3 months.

Regarding intraoperative conduct of laparoscopic cholecystectomy, there are $19.6 \%$ of respondents who do not use any filters intraoperatively. There are 51\% of respondents who still bring residents through surgery. More respondents perform laparoscopic cholecystectomy with 1 assistant during the pandemic from $76.5 \%$ to $90.2 \%$.

Laparoscopic cholecystectomy was first performed in Singapore in the early 1990 s where only $6.5 \%$ of acutely inflamed gallbladder operated were ELC. ${ }^{7,8}$ Today, more than $90 \%$ of surgeons surveyed in our study would perform ELC for AC. This is not surprising given the numerous benefits of ELC over DLC established in 


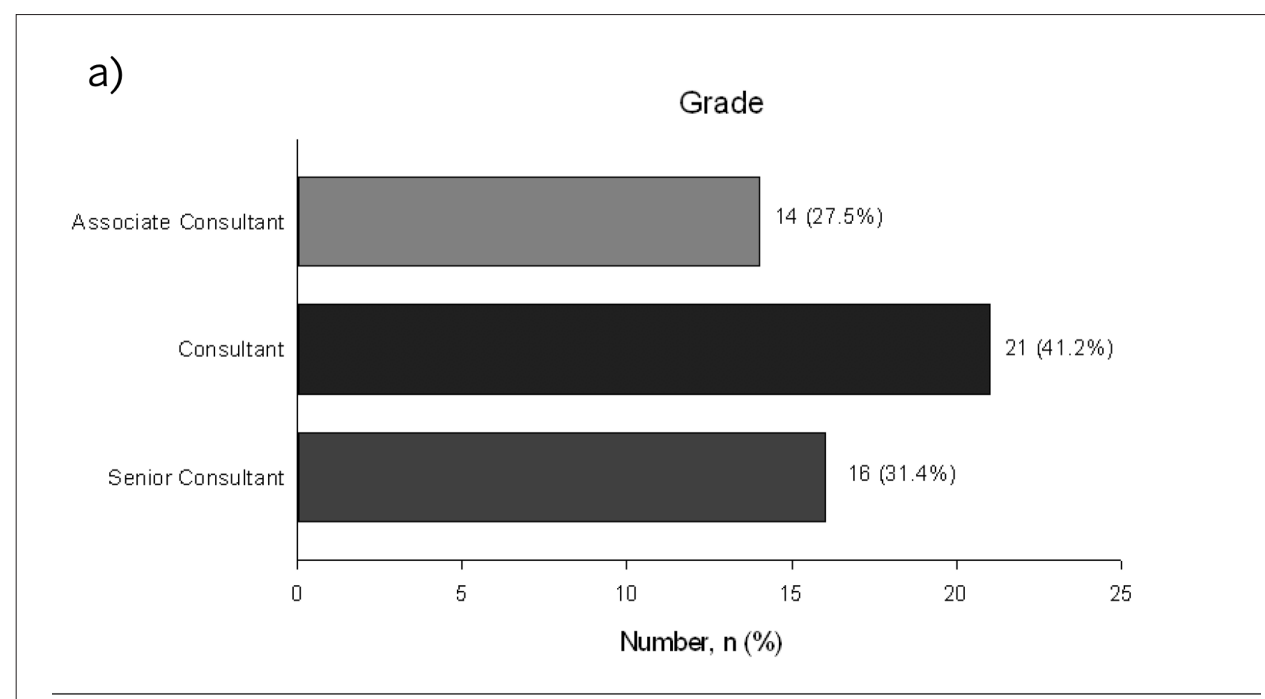

b)

Place of Practice

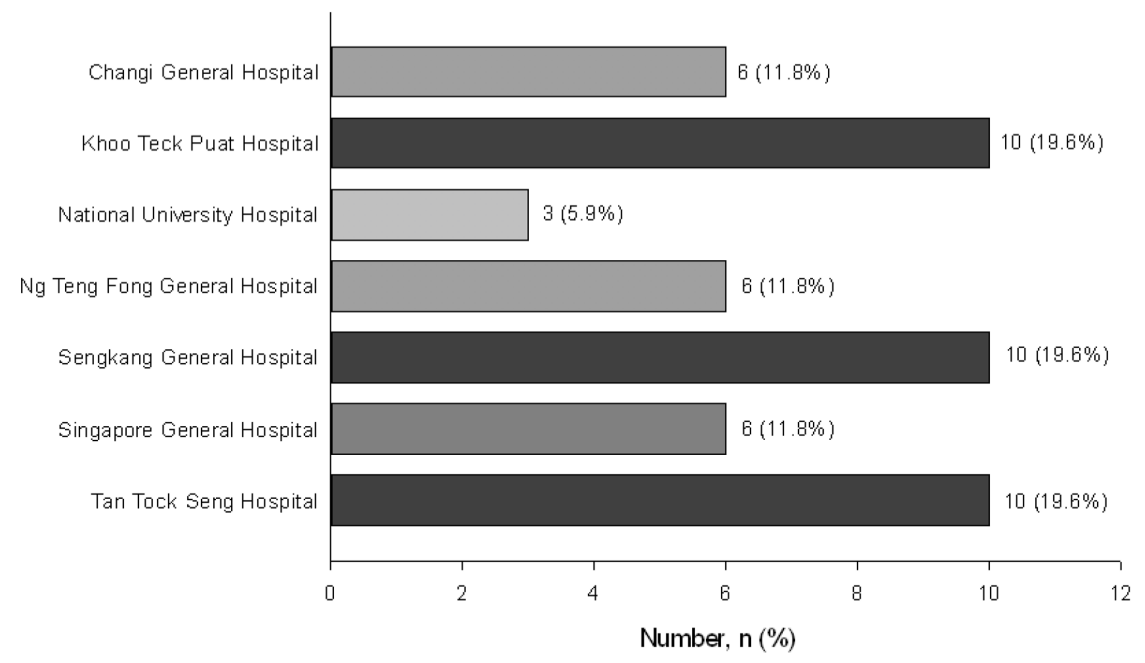

c)

Subspecialty

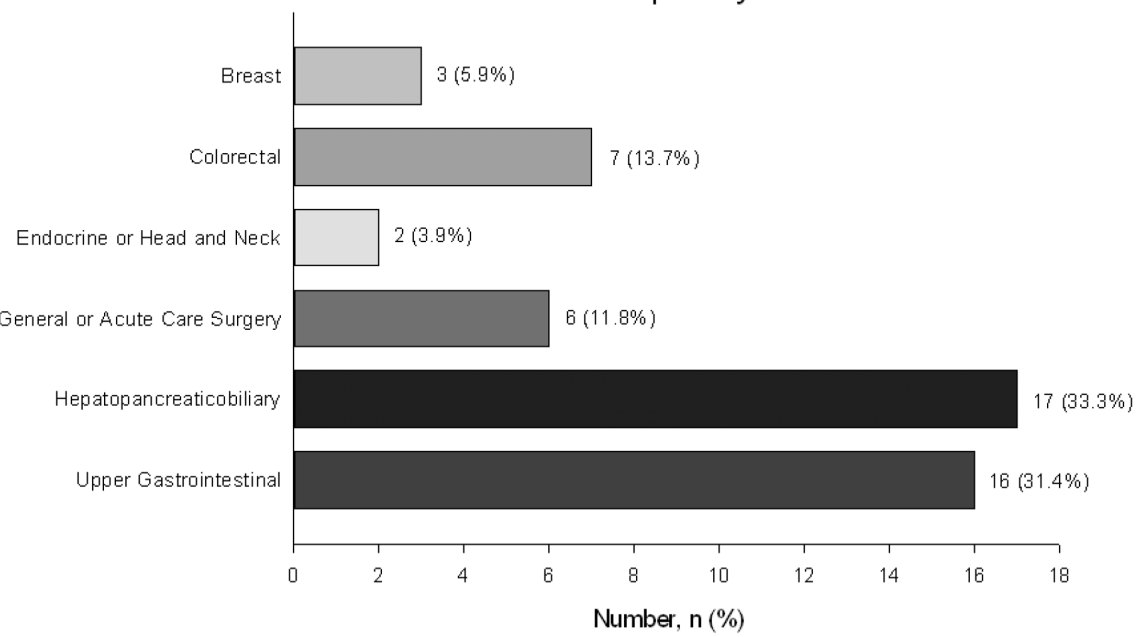

Fig. 1. Summary of (a) grade, (b) place of practice and (c) subspecialty of respondents 
Table 1. Screening and use of personal protection equipment (PPE) in the COVID-19 pandemic

$\begin{aligned} & \text { Survey questions on screening and PPE use } \\ & \text { Was any patient referred for acute cholecystitis tested positive for COVID-19 BEFORE surgery at your hospital (percentage)? } \\ & \begin{array}{l}\text { Number of } \\ \text { responses, }\end{array}\end{aligned}$
$\begin{array}{ll}1-5 \% & 65(88.2) \\ 5-10 \% & 6(11.8) \\ >10 \% & 0\end{array}$

Was any COVID-19 negative patient referred for acute cholecystitis later tested positive for COVID-19 at your hospital (percentage)?

$\begin{array}{ll}0 \% & 42(82.4) \\ 1-5 \% & 9(17.6) \\ 5-10 \% & 0 \\ >10 \% & 0\end{array}$

Since the COVID-19 pandemic, how has your hospital changed its organization?

My hospital is exclusively dedicated to COVID-19 patients 1 (2)

My hospital has restricted areas dedicated to COVID-19 patients 50 (98)

Do you routinely screen patients with acute cholecystitis for COVID-19 infection before surgery?

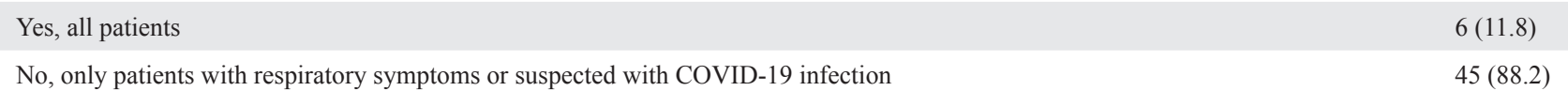

Would you change your overall strategy (index admission early cholecystectomy vs delayed interval

cholecystectomy) if you could test all patients?

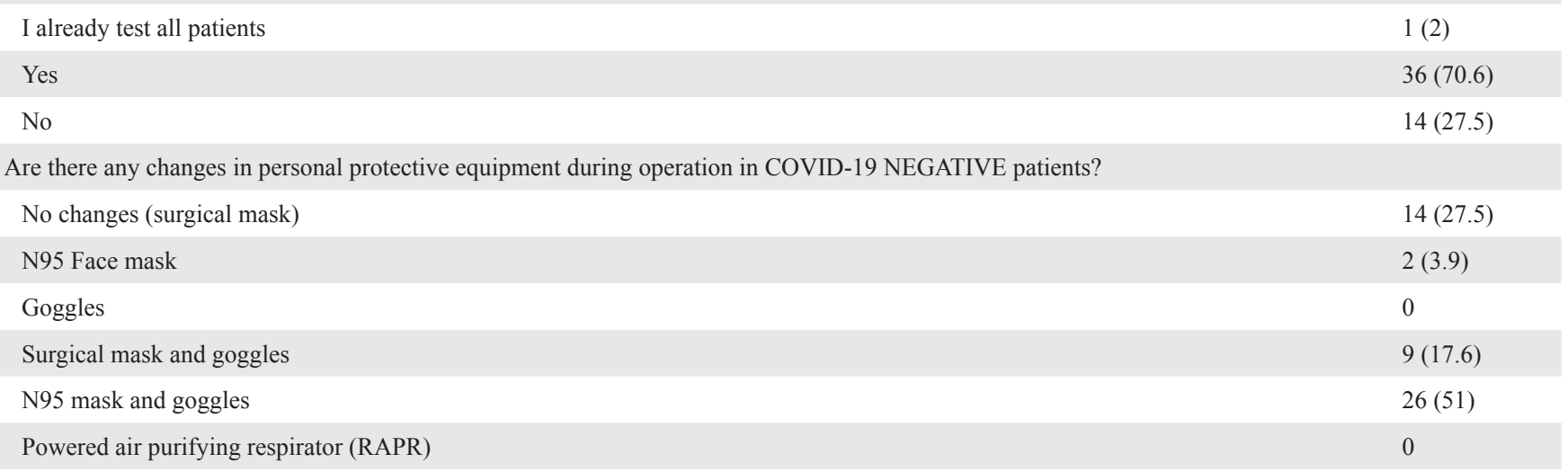

Are there any changes in personal protective equipment during operation in COVID-19 UNKNOWN (not tested) patients?

\begin{tabular}{|c|c|}
\hline No changes (surgical mask) & $10(19.6)$ \\
\hline N95 Face mask & $3(5.9)$ \\
\hline Goggles & 0 \\
\hline Surgical mask and goggles & $6(11.8)$ \\
\hline N95 mask and goggles & $32(62.7)$ \\
\hline Powered air purifying respirator (RAPR) & 0 \\
\hline \multicolumn{2}{|c|}{ Are there any changes in personal protective equipment during operation in COVID-19 POSITIVE patients? } \\
\hline No changes (surgical mask) & 0 \\
\hline N95 Face mask & 0 \\
\hline Goggles & 0 \\
\hline Surgical mask and goggles & 0 \\
\hline N95 mask and goggles & $24(47.1)$ \\
\hline Powered air purifying respirator (RAPR) & $27(52.9)$ \\
\hline
\end{tabular}


Table 2. Management of acute cholecystitis before and during the COVID-19 pandemic

\begin{tabular}{|lll|}
\hline Comparison before and during the pandemic & $\begin{array}{l}\text { Before } \\
\text { Number of } \\
\text { responses, } \mathrm{n}(\%)\end{array}$ & $\begin{array}{l}\text { During } \\
\text { Number of } \\
\text { responses, } \mathrm{n}(\%)\end{array}$ \\
\hline How many patients with acute cholecystitis are referred to your hospital in one month? & & $7(13.7)$ \\
\hline$<5$ & 0 & $15(29.4)$ \\
\hline $5-10$ & $10(19.6)$ & $22(43.1)$ \\
\hline $11-20$ & $26(51)$ & $7(13.7)$ \\
\hline$>20$ & $15(29.4)$ & $12(23.5)$ \\
\hline How many assistants do you require for laparoscopic cholecystectomy? & $39(76.5)$ & $5(9.8)$ \\
\hline 2 & & $46(90.2)$ \\
\hline 1
\end{tabular}

How do you manage UNCOMPLICATED acute cholecystitis (not gangrenous, emphysematous or presence of abscess) BEFORE COVID-19 pandemic?

Non-operative management with antibiotics

$0(0)$

$46(90.2)$

$9(17.6)$

Index admission early laparoscopic cholecystectomy

Delayed interval laparoscopic cholecystectomy

Did you change your attitude in the management of UNCOMPLICATED acute cholecystitis (not gangrenous, emphysematous or presence of abscess) during the COVID-19 pandemic?

$\begin{array}{llr}\text { Yes, for all patients } & \text { NA } & 15(29.4) \\ \text { Yes, only in COVID+ patients } & \text { NA } & 21(41.2) \\ \text { Yes, only in COVID+ and untested patients } & \text { NA } & 2(3.9) \\ \text { No } & \text { NA } & 13(25.5)\end{array}$

In percentage, how often is index admission early laparoscopic cholecystectomy used at your hospital (BEFORE COVID-19 pandemic) in patients with UNCOMPLICATED acute cholecystitis (no gangrenous, emphysematous or presence of abscess)?

\begin{tabular}{|c|c|c|}
\hline$<25 \%$ & $2(3.9)$ & NA \\
\hline $26-50 \%$ & $8(15.7)$ & NA \\
\hline $51-75 \%$ & $22(43.1)$ & NA \\
\hline $76-100 \%$ & $19(37.3)$ & NA \\
\hline
\end{tabular}

In percentage, how often is interval delayed laparoscopic cholecystectomy used at your hospital currently (DURING COVID-19 pandemic) in patients with UNCOMPLICATED acute cholecystitis (no gangrenous, emphysematous or presence of abscess)?

\begin{tabular}{llc}
$<25 \%$ & NA & $21(41.2)$ \\
$26-50 \%$ & NA & $22(43.1)$ \\
$51-75 \%$ & NA & $6(11.8)$ \\
$76-100 \%$ & NA & $2(3.9)$ \\
\hline Complicated acute cholecystitis & &
\end{tabular}

How do you manage haemodynamically stable COMPLICATED (gangrenous, emphysematous or presence of abscess) acute cholecystitis? 
Table 2. Management of acute cholecystitis before and during the COVID-19 pandemic (Cont'd)

\begin{tabular}{|c|c|c|}
\hline Comparison before and during the pandemic & $\begin{array}{l}\text { Before } \\
\text { Number of } \\
\text { responses, n }(\%)\end{array}$ & $\begin{array}{l}\text { During } \\
\text { Number of } \\
\text { responses, n }(\%)\end{array}$ \\
\hline Delayed interval laparoscopic cholecystectomy & $1(2)$ & $1(2)$ \\
\hline Index admission open cholecystectomy & $1(2)$ & $1(2)$ \\
\hline \multicolumn{3}{|c|}{$\begin{array}{l}\text { In percentage, how often is index admission laparoscopic cholecystectomy usually performed at your } \\
\text { hospital in patients with haemodynamically stable COMPLICATED acute cholecystitis (gangrenous, } \\
\text { emphysematous or presence of abscess)? }\end{array}$} \\
\hline$<25 \%$ & $2(3.9)$ & $12(23.5)$ \\
\hline $26-50 \%$ & $13(25.5)$ & $12(23.5)$ \\
\hline $51-75 \%$ & $17(33.3)$ & $18(35.3)$ \\
\hline $76-100 \%$ & $19(37.3)$ & $9(17.6)$ \\
\hline \multicolumn{3}{|c|}{ What is the interval duration that you would perform delayed interval laparoscopic cholecystectomy? } \\
\hline 6 weeks & $43(84.3)$ & $15(29.4)$ \\
\hline 8 weeks & $6(11.8)$ & $13(25.5)$ \\
\hline 3 months & $2(3.9)$ & $18(35.3)$ \\
\hline$>3$ months & 0 & $5(9.8)$ \\
\hline \multicolumn{3}{|c|}{$\begin{array}{l}\text { Did you change your attitude in the management of haemodynamically stable COMPLICATED acute } \\
\text { cholecystitis (gangrenous, emphysematous or presence of abscess)? }\end{array}$} \\
\hline Yes, for all patients & NA & $7(13.7)$ \\
\hline Yes, only in COVID+ patients & NA & $19(37.3)$ \\
\hline No & NA & $21(41.2)$ \\
\hline
\end{tabular}

\section{Intraoperative approach}

How do you / will you operate on patients with cholecystitis (if patients are operated on) in COVID-19 UNKNOWN (not tested) patients?

\begin{tabular}{|c|c|c|}
\hline Laparoscopic surgery with specific devices for protection and smoke evacuation & NA & $36(70.6)$ \\
\hline Laparoscopic surgery without specific devices for protection and smoke evacuation & NA & $10(19.6)$ \\
\hline Laparoscopic surgery, but I do not have devices for pneumoperitoneum/smoke evacuation & NA & $5(9.8)$ \\
\hline Laparoscopic surgery, but hospital policy does not allow it & NA & 0 \\
\hline Prefer open surgery & NA & 0 \\
\hline Not applicable & NA & 0 \\
\hline
\end{tabular}

How do you / will you operate on patients with cholecystitis (if patients are operated on) in COVID-19 POSITIVE patients?

Laparoscopic surgery with specific devices for protection and smoke evacuation

NA

$39(76.5)$

Laparoscopic surgery without specific devices for protection and smoke evacuation

NA

2 (3.9)

Laparoscopic surgery, but I do not have devices for pneumoperitoneum/smoke evacuation

NA

$0(0)$

Laparoscopic surgery, but hospital policy does not allow it

NA

$1(2)$

Prefer open surgery

NA

7 (13.7) 
Table 2. Management of acute cholecystitis before and during the COVID-19 pandemic (Cont'd)

\begin{tabular}{|c|c|c|}
\hline Comparison before and during the pandemic & $\begin{array}{l}\text { Before } \\
\text { Number of } \\
\text { responses, n (\%) }\end{array}$ & $\begin{array}{l}\text { During } \\
\text { Number of } \\
\text { responses, n (\%) }\end{array}$ \\
\hline \multicolumn{3}{|l|}{ If laparoscopic cholecystectomy is performed, do you use any filter system? } \\
\hline Yes, for all patients & NA & $23(45.1)$ \\
\hline Yes, only in COVID+ patients & NA & $12(23.5)$ \\
\hline Yes, only in COVID+ and untested patients & NA & $6(11.8)$ \\
\hline No & NA & $10(19.6)$ \\
\hline \multicolumn{3}{|l|}{ If any evacuation system with filters is used, which type of device do you use? } \\
\hline Commercially available & NA & $34(66.7)$ \\
\hline Commercially available with filtration connected to a container with water & NA & 0 \\
\hline Commercially available with filtration connected to a sealed container & NA & $14(27.5)$ \\
\hline Homemade & NA & $2(3.9)$ \\
\hline Homemade with filtration connected to a container with water & NA & 0 \\
\hline Homemade with filtration connected to a sealed container & NA & $1(2)$ \\
\hline \multicolumn{3}{|c|}{$\begin{array}{l}\text { Do you still bring residents through laparoscopic cholecystectomy for acute cholecystitis during the } \\
\text { COVID-19 pandemic? }\end{array}$} \\
\hline Yes & NA & $26(51)$ \\
\hline No & NA & 25 (49) \\
\hline
\end{tabular}

NA: Not applicable

meta-analysis and Cochrane reviews., ${ }^{4,5}$ Thus, the need to rationalise resources and postpone surgeries in this pandemic poses a clinical equipoise with regards to the management of AC.

Despite pandemic-specific guidelines recommending medical treatment of gallstone related issues, ${ }^{3} 58.8 \%$ of surgeons in our study would still perform ELC for uncomplicated acute cholecystitis. The need for possible longer length of stay for pain control and observation for development of complications related to failure of medical treatment may be a consideration for proponents of ELC. This should be balanced with the counterargument of operating on the asymptomatic or presymptomatic COVID-19 patient and exposing the patient to risk of respiratory complications and need for ICU admission. Clearly, there is no 'one size fits all' guideline that is appropriate for every situation, and ultimately the decision to operate lies in the discretion of the surgeon taking into consideration the disease prevalence and infection control measures in the country and community.

Currently, the indications for testing patients for COVID-19 prior to surgery would include patients with active respiratory tract symptoms or patients belonging to a high-risk group such as an individual residing in a dormitory. Beyond that, routine preoperative COVID-19 screening has yet to be advocated in Singapore. Routine preoperative screening may be an option to consider for ELC with the American College of Surgeons (ACS) recommending rapid testing for COVID-19 infection through real-time reverse transcriptase polymerase chain reaction (RT-PCR) testing to be considered for all patients undergoing planned surgery. ${ }^{9}$ This is plausible given that uncomplicated $\mathrm{AC}$ is a semi-emergency and therein lies the window of opportunity for testing and turnaround of test results if the patient is haemodynamically stable. Currently, $11.8 \%$ of surgeons in our study perform routine preoperative 
screening for COVID-19 with $70.6 \%$ of surgeons claiming that their management strategy may alter if it was possible for them to routinely test all patients going for surgery. This approach would however also be influenced by the COVID-19 diagnostic testing capability and turnaround times of each institution.

The choice of PPE in COVID-19 positive patients is also another interesting area that our study has found surgeons split in equal proportions between the use of N95 masks and goggles versus PAPR. There have been some concerns regarding the ability of N95 masks to prevent inhalation of particles in surgical smoke given that N95 masks filter particles larger than $0.3 \mu \mathrm{m}$, while generated particles range from 0.07 to $0.42 \mu \mathrm{m}$, and the size of COVID-19 (SARS-Cov-2) virus ranges from 0.06 to $0.14 \mu \mathrm{m} .{ }^{10}$ This should however be taken in the context of the laparoscopic setup being a closed-circuit and containment environment with regulated inflow and outflow of gas that can be further mitigated by the application of commercial Ultra Low Particulate Air (ULPA) filters that have been quoted to filter $99.999 \%$ of particles greater than $0.05 \mu \mathrm{m}$ if it conforms to the standards of the Association of periOperative Registered Nurses (AORN). Currently 19.6\% of surgeons in our study do not use any filter system and should reconsider for COVID-19 positive cases.

Interestingly, there are also $13.7 \%$ of surgeons in our study who would prefer to perform open cholecystectomy for COVID-19 patients. The debate over the safety of open versus laparoscopic approach specific to the pandemic is a controversial topic that is constantly evolving. A study by Zheng et al. $(2020)^{11}$ definitely seems to suggest greater risk associated with laparoscopy pertaining to electrocautery-induced aerosolisation and creation of surgical plume whereas guidelines from Society of American Gastrointestinal and Endoscopic Surgeons (SAGES) and Royal Australasian College of Surgeons (RACS) state that little or no evidence favors for or against the specific use of open over laparoscopic approach. ${ }^{12,13}$

The need to minimise the number of essential personnel and exposure in the operating room is one that is articulated by both SAGES and ACS. ${ }^{12,14}$ This is also reflected in our study with the number of surgeons performing laparoscopic cholecystectomy with one assistant increasing from $76.5 \%$ to $90.2 \%$ before and during the pandemic respectively. Furthermore, only $51 \%$ of consultants bring residents through cases during this period, which would inevitably impact residents' training and experience. The potential loss of operating time has prompted the use of realistic virtual surgical simulation in an attempt to mitigate this problem. ${ }^{15}$ More importantly, the temporary loss in opportunities for technical skills is compensated by the acquisition of values and principles of prioritisation and ethics learnt in this pandemic that will contribute to the overall holistic growth of the surgical resident.

We acknowledge the limitations of our study being the time frame in which this survey was performed. With the escalating case numbers in Singapore due to the recent explosion of COVID-19 in migrant worker clusters, this may influence the practices and strategies of surgeons on the ground. Furthermore, the respondent rate of this survey is limited at $69.9 \%$ but there is tradeoff in the high multicenter responses obtained that enables us to sample the practices across all major public institutions in Singapore.

The challenges and impact of COVID-19 on AC management in Singapore is evident from our survey. With this collaborative survey reflecting local practices during this crisis, we hope that this will pave the way for future multicenter studies to corroborate perception with clinical data on the management of AC both during COVID-19 and in peacetime.

\section{REFERENCES}

1. Hsu LY, Chia PY, Lim JF. The Novel Coronavirus (SARS-CoV-2) Epidemic. Ann Acad Med Singap 2020;49:105-7.

2. Lei S, Jiang F, Su W, et al. Clinical characteristics and outcomes of patients undergoing surgeries during the incubation period of COVID-19 infection. EClinicalMedicine 2020;21:100331.

3. American College of Surgeons. COVID-19: Elective Case Triage Guidelines for Surgical Care, March 2020. Available at: https:// www.facs.org/covid-19/clinical-guidance/elective-case. Accessed on 7 May 2020.

4. Gurusamy KS, Davidson C, Gluud C, et al. Early versus delayed laparoscopic cholecystectomy for people with acute cholecystitis. Cochrane Database Syst Rev 2013;6:CD005440.

5. Sutton AJ, Vohra RS, Hollyman M, et al. Cost-effectiveness of emergency versus delayed laparoscopic cholecystectomy for acute gallbladder pathology. Br J Surg. 2017;104:98-107.

6. Yokoe M, Hata J, Takada T, et al. Tokyo Guidelines 2018: diagnostic criteria and severity grading of acute cholecystitis (with videos). J Hepatobiliary Pancreat Sci 2018;25:41-54.

7. Kum CK, Goh PM. Laparoscopic cholecystectomy: the Singapore experience. Surg Laparosc Endosc 1994;4:22-4.

8. Kum CK, Chua TE. Management of acute cholecystitis in the era of laparoscopic surgery. Ann Acad Med Singap 1996;25:640-2.

9. American College of Surgeons. Local Resumption of Elective Surgeries Guidance. Available at: https://www.facs.org/covid-19/clinicalguidance/resuming-elective-surgery. Accessed on 7 May 2020. 
10. Limchantra IV, Fong Y, Melstrom KA. Surgical Smoke Exposure in Operating Room Personnel: A Review. JAMA Surg 2019;154:960-7.

11. Zheng MH, Boni L, Fingerhut A. Minimally Invasive Surgery and the Novel Coronavirus Outbreak: Lessons Learned in China and Italy. Ann Surg 2020;272:e5-6.

12. Society of American Gastrointestinal and Endoscopic Surgeons. SAGES and EAES Recommendations Regarding Surgical Response to COVID-19 Crisis, March 2020. Available at: https://www.sages. org/recommendations-surgical-response-covid-19. Accessed on 7 May 2020

13. General Surgeons Australia \& RACS Australian Board in General Surgery and New Zealand Association of General Surgeons \& RACS New Zealand Board in General Surgery. COVID-19 Guidelines for General Surgery, March 2020. Available at: https://umbraco.surgeons. org/media/5160/doc-2020-03-31-covid-19-guidelines-for-generalsurgery_final_updated.pdf. Accessed on 7 May 2020.

14. American College of Surgeon. COVID-19: Considerations for Optimum Surgeon Protection Before, During, and After Operation. Available at: https://www.facs.org/covid-19/clinical-guidance/surgeonprotection. Accessed on 7 May 2020.

15. Kowalewski KF, Hendrie JD, Schmidt MW, et al. Validation of the mobile serious game application Touch Surgery ${ }^{\mathrm{TM}}$ for cognitive training and assessment of laparoscopic cholecystectomy. Surg Endosc 2017;31:4058-66.
Clement LK $\underline{\text { Chia }},{ }_{F R C S(E d)}^{1}$, Han Boon $\underline{\mathrm{Oh}},{ }^{2}{ }_{F R C S(E d)}$, Tousif $\underline{\text { Kabir}},{ }^{3} F R C S(E d)$, Yen Pin $\underline{\text { Tan }},{ }^{4} F R C S(E d)$, Nita Thiruchelvam, ${ }^{5}$ FRCS (Ed), Ning Qi Pang, ${ }^{6}$ FRCS, Kai Siang Chan, ${ }^{1} M B B S$, Ye Xin $\underline{\text { Koh }},{ }^{7} F R C S(E d)$

\footnotetext{
${ }^{1}$ Department of General Surgery, Khoo Teck Puat Hospital, Singapore ${ }^{2}$ Department of General Surgery, Ng Teng Fong General Hospital, Singapore ${ }^{3}$ Department of General Surgery, Sengkang General Hospital, Singapore ${ }^{4}$ Department of General Surgery, Tan Tock Seng Hospital, Singapore ${ }^{5}$ Department of General Surgery, Changi General Hospital, Singapore ${ }^{6}$ Division of Hepatobiliary \& Pancreatic Surgery, National University Hospital, Singapore

${ }^{7}$ Department of Hepatopancreatobiliary and Transplant Surgery, Singapore General Hospital, Singapore
}

Address for Correspondence: Adj Asst Prof Clement LK Chia, Department of General Surgery, Khoo Teck Puat Hospital, 90 Yishun Central, Singapore 768828 .

Email: clemchia84@gmail.com 